\title{
Exploring Culture as a Paradox: Complementary QUEUE analysis of cultural values and practices
}

\begin{tabular}{|r|l|}
\hline Journal: & Journal of Organizational Change Management \\
\hline Manuscript ID & JOCM-02-2019-0053.R4 \\
\hline Manuscript Type: & Research Paper \\
\hline Keywords: & Cultural duality, Paradox, Conscious, Unconscious, QUEUE analysis \\
\hline \multicolumn{2}{|l}{} \\
\hline
\end{tabular}




\title{
Exploring Culture as a Paradox: \\ Complementary QUEUE analysis of cultural values and practices
}

\begin{abstract}

\section{Purpose}

The main proposition presented by this paper is that culture in international management has been dominated by a "Western dualism to measuring culture" (Caprar et al., 2015: 1024), which has resulted in severe problems and persistent limitations. The suggestion is that cultural research can be more productively conceived as a paradox involving a duality between two contrasting yet co-determined spheres or domains.
\end{abstract}

\section{Design/methodology/approach}

The paper provides an outline of culture as a paradox and an outline of a research approach to address the dualities of culture.

\section{Findings}

A cultural duality is described, which involves a paradoxical 'yin-yang' relationship between two contrasting yet mutually constituted aspects of the collective mind. One domain, which involves conscious cognitive elements has dominated research characterised by positivism and empirical cross-cultural explorations of phenomenological cultural values. The second, more recondite domain, involves unconscious and embodied cultural phenomena, which are more tacit and hidden in indirect expression through communicative interaction, exchanges of symbolic representations and embodied behaviour in context.

\section{Research limitations/implications}

A methodological duality of qualitative and quantitative mixing in order to provide a bi-focal understanding of both tacit and explicit aspects of culture is proposed as a research agenda.

\section{Originality/value}

The suggestion is that these cultural shadows have been relatively neglected thus far in crosscultural management research. This means that in order to better comprehend culture as paradox, an equalization of approaches sensitive to both sides of the duality is prescient. In pursuit of this idea, a complementary qualitative analysis directed at more nebulous cultural phenomena is proposed in order to provide a balanced analysis of culture as paradox.

Keywords: Cultural duality, Paradox, Conscious, Unconscious, QUEUE analysis 


\section{Introduction}

Cultural explorations for the last 40 or so years have been dominated by the 'national cultural model' (McSweeney, 2009) as characterized by Hofstede (1980, 2001) and GLOBE researchers (House et al., 2004), which emphasize identifying nomothetic cultural dimensions of values. The emphasis upon measuring conscious values has resulted in less focus upon more nebulous, unconscious and embodied aspects of culture. This includes little attention paid to cultural practices, which are more reflective of unconscious thought and tend to be more local, 'emic' and embodied. Hofstede's view has been that practices are the external surface of the 'cultural onion' whose core is values. He maintains that practices are more important at organizational level than at a national level of culture. GLOBE researchers have been perturbed by a negative correlation between social values and social practices in their surveys and a convincing explanation of this still remains elusive. In an attempt to explain this enigma, Brewer and Venaik (2010) have nominated different reasons for negative correlations between social practices and social values across different dimensions of the GLOBE study. In this paper, our proposition is that these anomalies register because values and practices occupy two paradoxically opposing yet complementary realms of cultural duality, which are not adequately and comparatively accessible by a singular methodology or unitary paradigm. We use the term duality to emphasize the notion of interdependence between cultural elements, which makes it different from dualism. Duality refers to conceptually distinct, yet interdependent elements, dualism on the other hand is the division into separate, opposing pairs of elements (Jackson, 1999). The suggestion is that social practices occupy an 'unconscious embodied' domain of cultural experience, an aspect of culture as a paradox, which has been largely overlooked. As a result, a paradoxical approach to culture suggests that interaction between cultural practices and values generates emergent cultural phenomena. In this conception, looking for the dependent and independent variables involved is rather futile because paradoxical creations of culture are emergent from the fusion of two contrasting yet co-determining forces. Culture in international management research has traditionally not been seen as a paradox and this may, itself, be one of culture's consequences. The notion of paradox itself appears to be culture-bound as some cultures are more receptive to such ambiguity than others. For example, Keller et al. (2017) demonstrate that Chinese and American respondents have different mindset towards paradox and enact different paradoxical frames when faced with the same behavioural conditions.

The enigmatic cultural domain of principal interest in this paper is unconscious, prelinguistic and is manifested mostly in embodied affect and sensory perception, which has a 
greater influence upon tacit knowledge than explicit knowledge. In other words, problems in describing culture may be a result of a cultural preference to avoid paradox and focus on the entitative and directly measurable at the expense of indeterminate cultural penumbra, which are the silent, enigmatic, 'unconscious embodied' side of cultural paradox. The difficulty is that the indirectly disclosed cultural forces are not directly knowable and only have indirect and shadowy effects because they are principally unspoken, ineffable and tacit. These cultural 'noumena' are not directly accessible because they are not phenomenological. Their shadows manifest themselves symbolically through, for example, the metaphors and tropes used in cultural interaction. Their influence is held mainly in the unconscious minds of cultural actors, who cannot usually articulate them except symbolically through analogies, figuration, tropes or gestures. The proposal is that the exchange between social practices and social values is seldom direct and overwhelmingly is mediated by these tacit, cultural aspects of unconscious, embodied cultural symbols.

The paper proceeds by constructing an argument for recognition of the importance of this more tacit cultural domain whilst accepting that understanding these cultural shadows is also subject to a symbolic nexus. In other words, as cultural observers, researchers too can only really understand these cultural shadows symbolically in terms of other signs. Our use of the metaphors of shadows, 'yin-yang', onions, paradox, noumena etc. so far helps us recognise that exploration of symbols is conducted with reference to other symbols. To assist in explaining this agenda, theories from psychoanalysis, embodiment and practice are marshalled in this paper. All of these diverse sources have in common the importance of identifying more indeterminate, paradoxical, concealed or invisible cultural symbols that resist or defy the application of metrics. The enigmatic cultural domain in question is regarded as located at a chiasmus between consciousness, the unconscious mind and the sensing body.

There have been both quantitative and qualitative investigations into embodied human emotion and intuition, particularly within psychology inspired by the Jungian conception of the dynamics of a 'cultural unconscious' (Henderson, 1990). This suggests that there is an intermediate level of the unconscious between the deep unconscious and conscious mind that is accessible by both positivist and interpretivist methods. These dynamic, unconscious 'cultural complexes' (Singer and Kaplinsky, 2010) become reflected in cultural attitudes and behaviours. The agenda of this paper is that we are, in addition, interested in looking into deeper unconscious embodied and more 'shadowy', paradoxical reflections that are cultural complexes beyond the reach of metrics. The depths of this enigmatic, sublime domain 
beneath the intermediate level of the cultural unconscious cannot be directly accessed and can be best understood mediated by more symbolic, artistic and poetic, qualitative representations than by numbers. In other words, approaches aimed at understanding these ineffable and enigmatic forces must accept that both the tacit, deeply unconscious cultural domain under scrutiny and the attempted descriptions of it cannot be restricted to directly objectivist measurement. The suggestion is that this domain may never be entirely understood in unmediated terms but that this should not detract from the possibility of reducing ignorance of it through creative abduction.

As a result, the proposal in this paper is to initiate a complementary approach to the 'national cultural model' (McSweeney, 2009) that we are calling Questioning Unconscious and Embodied Unrepresented Effects (QUEUE) towards cultural investigations. Such a 'depth paradigm' (Yakushko et al., 2016) is, of course, proposed as very different in terms of ontology, epistemology and methodology to the national cultural model. These differences require exploring through paradigm interplay in an attempt to develop an understanding of culture as a paradox. In attempting to deal with this cultural duality, 'paradigm crossing', as outlined by Schultz and Hatch (1996), proposes engaging multiple paradigms requiring the cognitive flexibility to accept the coexistence of multiple truths and the expectation of benefits of mutual arising from the synthesis of apparent opposite underlying assumptions (Lowe et al., 2007). In this paper, we outline a 'sequential paradigm crossing' approach, suggesting that a QUEUE investigation of unconscious embodied cultural influences can be used to identify whether participants in such an exercise subsequently respond differently to GLOBE questions relating to social values and practices than a control group of nonparticipants. We now turn to explore culture as a paradox by exploring it as a duality of two halves of a story.

\section{The national cultural model as half of the story}

Cultural explorations in organizations for the last 40 or so years have been dominated by the 'national cultural model' as characterized by Hofstede and GLOBE researchers, which emphasize identifying nomothetic dimensions of cultural values. The national cultural model has merits and has certainly been durable within cultural analysis in international management. Beugelsdijk et al. (2017), for example, review the progress of Hofstede inspired research and maintain that the improvements called for by Kirkman et al. (2006) have been largely satisfied. Kluckhohn and Strodtbeck (1961), Hofstede (1980, 2001), Schwartz (1992), Trompenaars (1988) are early influential contributors to the national 
cultural model or 'cross-national comparison perspective' (Sackmann and Philips, 2004). They mostly subscribe to functionalism as the dominant and 'cherished' scientific paradigm (Boyacigiller and Adler, 1991). They usually subscribe in Burrell and Morgan's (1979) terms to 'functionalism' through objectivist assumptions about epistemology, methodology and ontology. Their purpose in the main is to construct universal nomothetic theory using the legitimized 'rigour' of positivism (Boyacigiller and Adler, 1991). The national cultural model has been increasingly under attack. McSweeney (2009: 945) maintains the effect of the national cultural model is to over-privilege continuity and uniformity and berates its "single simplistic uni-causal mentalist" geographical determinism. The controversy around crosscultural research has also raised questions regarding level of analysis (country level vs individual level), research paradigms (universalist versus contextual, etic versus emic; objectivist versus subjectivist; functionalist versus interpretivist) and methodologies appropriate for measuring culture (quantitative versus qualitative or mixed methods). For a more detailed discussion see Kirkman et al., 2006; Caprar et al. 2015, Patel, 2017; Romani et al. 2018)

The emphasis within the 'national cultural model' upon nomothetic macro-level values resulted, before GLOBE, in little focus upon social practices, which tend to involve more local, 'emic' and embodied action. The incorporation of social practice questions in the GLOBE questionnaire resulted in an unexpected negative correlation between social values and social practices and a convincing explanation of this still remains elusive. In this paper, the proposition is that the national cultural model is limited by an insistence of emphasis upon directly measurable cultural forces mostly through a focus on conscious and articulated values. This does not capture an adequate understanding of social practices, which incorporate situated unconscious and embodied influences that are not directly measurable. Osland and Bird (2000) have demonstrated that cultural sensemaking needs to consider social practices at the local level. Values are only meaningful when enacted within situated cultural interactions. Such situated enactment is largely accomplished through a degree of purposive decision-making that draws from knowledge derived from embodied experience.

\section{Unconscious embodied culture as a second half of the story}

In this section of the paper, we explore how unconscious and embodied cultural phenomena have been conceived. These approaches tend to emphasise the body and its role in symbolic interaction as the principal vehicle for expressions of unconscious thought. Within this perspective, an important mediating role of discourse and language is a common theme. In 
other words, this view regards indirect symbolic interaction, mostly through figurative language, as a catalyst between an embodied unconscious and conscious cognition.

\section{Unconscious embodiment}

A diverse literature, from various disciplines, alludes to unconscious embodiment. This realm as described by William James is one of pure, embodied experience un-warped by theories. Wittgenstein calls it a 'rough ground' of raw, lived experience (Chia, 2019). Vico was amongst the first to identify the embodied imagination as 'Senti ergo sum' in opposition to Descartes' Cogito. In other words, unconscious embodied subjectivity and cognitive rationality can be regarded as a duality; each is paradoxically contained within the other in dynamic conflict but mutual constitution. Chen (2018) explores the paradoxical relations between opposing permanent and relative cultural elements. This means for example that Individualism and Collectivism in some contexts can both be high in a cultural condition of ' commutarianism'. If human culture contains both subjectivity and objectivity as a 'yin-yang' duality (Chen, 2018), it follows that neither extreme of absolute relativism nor totalizing scientific objectivity are really very useful independently. This suggests that the concerns of objectivist / rationalist and subjectivist / interpretive research are paradoxically complementary in that they are 'two sides of a coin' forming a duality whose separation into paradigmatic silos is counter-productive.

Unconscious and embodied cultural forces are those which are prior to values, beliefs and underlying assumptions and prior to articulations of ideas, preferences and expectations. These "shadowy dimensions of human functioning" (Arnaud and Vanheule, 2013: 1665) in the embodied unconscious do not ontologically exist, they cannot be reliably measured or adequately articulated through an 'immaculate perception'. Their initial, indirect expression would be in action through embodied affects, intuitions, gestures, sensory perceptions and tropes. However, these are more of a symptom or signified shadows rather than the actual unconscious forces at play. An ethnography of investment bankers conducted by Michel (2015) provides a good example of some possible indirect implications of this. Within this Wall Street sub-culture, the symbolic environment was replete with empty signification about work-life balance but the physical (embodied) environment was designed to cultivate approved visibility and promotion of overwork and presenteeism. The bankers, in other words, were motivated more by the (unconscious) silent language of a surveillance culture of overwork than a (conscious) rhetoric of work-life balance and only changed their behaviour when their bodies 'told them' through exhaustion, burn-out and illness to stop. This means 
that the body may be regarded as the ground of conscious thought and, simultaneously, a mediator for the depths of the unconscious. The body, in other words, has more than one schematic influence in relation to mind and is critical function in providing connections between the conscious and unconscious aspects of mind.

Within the organization studies literature, the notion of embodied knowledge has been contrasted with embrained, encultured, embedded and encoded knowledge (Blackler, 1995; Williams, 2007). Embodied knowledge is acquired by doing and depends on situated physical presence and sensory information. This makes it distinct from the other types of knowledge such as embrained knowledge (cognitive skills and conceptual abilities), encultured knowledge (depends on language and creating shared understandings), embedded knowledge (identified in systematic routines adopted in certain contexts) and encoded knowledge (signs and symbols that convey information).

Gabriel (1995) describes organizational realities driven by unconscious embodied desires, anxieties and emotions with the term 'unmanaged organization'. From this perspective, organizations are always a paradoxical space resulting from a duality between the conscious managed organization and the unconscious embodied unmanaged organization. That is to say, organizational cultures are a 'yin-yang' duality of both rational / objective and nonrational / subjective elements. The paradoxes and duality of forces of manageability and unmanageability can be regarded as persistently contradictory yet co-determined over time. From a Jungian perspective, the collective unconscious is at work in the unmanageable organization. The collective unconscious contains cumulative experiences inherited through evolution and passed down through predispositions described by Jung as archetypes, which transmit inherited emotional reactions to situations that frame unconscious responses to events (Gabriel and Carr, 2002; Fotaki et al., 2012).

The notion of unconscious embodiment has a long history of conceptual development within different disciplines using different terminologies. Merleau-Ponty (1962) has identified the embodied subject as employing a pre-reflective 'skilful coping' in order to abductively improvise a practical way through everyday problems based upon experience. Gibson (1966) identified 'affordances' as embodied sensory capabilities that the practitioner uses unconsciously and automatically in order to skilfully judge appropriate action in any situated context. In a similar vein, Damasio (1996) identifies 'somatic markers' as embodied memories unconsciously gained through experience that provide visceral, instinctive responses to situated events. Varela et al. (1991) identify the embodied mind as 'autopoetic' in terms of its ability as a living, sensing entity in making, without conscious reasoning, its 
own identity and recognising selective aspects of environments that enable appropriate adaptation. Lakoff and Johnson (1999) identify embodied cognition or 'embodied realism' which recognises all thought as symbolically embodied, mostly unconscious and predominantly metaphorical at source.

Wright (2017: 3) complains about a prevailing cognitivist approach to organizational research, where non-specific 'people' conceptualized as 'actors' in the performance of a routine are too often reduced to dis-embodied, generalised, de-contextualized script-enactors rather than "fully embodied actors who through their gestures, gaits, movements, silences, facial expressions, and bodily responses produce and reproduce organizational routines". This is an appreciation that situated, practical and adaptive embodied know-how requires unconscious competences in terms of habits and improvisational competency that require fully embodied engagement. Küpers and Pauleen (2015) outline serious consequences of over-reliance upon 'cogni-centric' regression of reason in contemporary corporate cultures as a consequence of failure to develop practical, embodied wisdom or phronesis. They regard disembodied approaches as resulting in managerial obsession with bottom-line financial criteria for success and a prevailing unwise propensity to conflate ends with means. A consequence of this is clear in an ethnographic study of a natural food cooperative (Ashforth and Reingen, 2014). This study identified a 'schizophrenic' organizational culture due to a split between dualistic and competing ideologies. Resolutions of ideological conflicts were accomplished in this case through embodied, pragmatic actions as 'good moves', peacekeeping decisions and rituals that had the effect of supressing conflict before it spiralled into vicious circles.

Unconscious embodiment and how the senses and the body influence meanings are culturally bound (Kastanakis and Voyer, 2014). Although cultures with a Cartesian psychostructure may privilege conscious cognition and reason over unconscious embodiment and emotion, this is not universal. In Buddhist cultures, such as Thailand for example, unconscious embodied influences are not denigrated and the psychostructure is suffused with a latent concern for emotion, 'face' and sensitivity towards the sensibilities of others through the figuration of kreng jai ('awe heart' or sensitive consideration of feelings of others). Indeed. the principal notion of karma, which means 'action' emphasises sensitive, unconscious embodiment. The philosophy holds that virtuous, pro-social karmic, embodied actions provide the potentials for social and spiritual improvement. Actions cultivated through mastery of unconscious positive emotions will, through karmic force, create positive futures but in an untethered unconscious mind, negative emotions will arise and negative 
futures will result of damage and resentments to senses and sensibilities. Thus, in Thai culture, unconscious embodiment appears to play a more prominent role and has different consequences for identity work, language and cognition than comparatively in Western cultures (Lowe et al., 2014). These unconscious forces do, of course, find expression in Thai discourse and in Buddhist ideas but, the main point is, much of it is latent, pre-conceptual, felt and unspoken. Neither the unspoken and unclassified force (or $C h{ }^{\prime} i$ in Chinese Taoism) of nature nor the Tao (the path or way towards enlightenment) is suitable for language, instruction and conceptual representations and can only be accessed only through mindful enactment of silent, embodied, meditative skills and tacit understanding.

This paper proposes that the key to understanding these shadowy phenomena is as a duality rather than through dualism. The dualism of the national cultural model with its prevalent binary distinctions such as individualism / collectivism is of little use here. Unconscious embodiment involves characteristically 'both / and' fusions rather than 'and/ or' distinctions. It is quantum-like in being paradoxical, indeterminate, emergent and resistant to organization or identity (Chia, 2019). Dualities are characteristically paradoxical, constituted by their "contradictory yet interrelated elements that exist simultaneously and persist over time" (Smith and Lewis, 2011: 386). Returning to Taoism, the notion of yin-yang refers to this sort of paradoxical duality (Chen, 2018). Within this realm nothing exists as an absolute 'black or white' alternative and everything is characterised as defined through interanimation with its opposite in mutual dynamically evolving, contradictory tensions of conflict-co-operation. Again, there appear to be cultural concomitants of orientation to duality. In some cultures of the East where engagement with duality is a central element of traditional philosophies, exclusion of it within Western dualistic cultural investigations can be regarded as cultural ethnocentrism. Fang (2009: 169) has examined some of the implications of Eastern (yin / yang) thinking and calls for more "self-confidence and courage in researching and globalizing indigenous Asian wisdom to advance management knowledge with global relevance". The suggestion is that the dominant national cultural model was developed in the West, through a Western lens and with Western dualistic 'and /or" priorities. A re-balancing towards cultural duality and paradox, which brings with it the necessity for a more equal attention toward unconscious embodiment is at the same time an attempted adoption of a more geo-centric orientation to cultural investigation. 


\section{QUEUE cultural investigations}

QUEUE cultural investigations involve the qualitative exploration of more nebulous cultural forces through indirect means usually using projective techniques. The assumption is that direct access to the dualities of culturally sublime influences is not possible.

In order to engage with the sublime cultural realm of what might be called 'unconscious embodiment', indirect proxies provide necessary mediated access. Within studies of culture and organization, Smircich (1983) includes the unconscious in terms of 'unconscious processes within organizations' as a recognizable research theme characterised by identifiable underlying assumptions and metaphors. In terms of embodiment and culture, Csordas (1993) in exploring 'Cultural Phenomenology' focuses upon 'semantic modes of attention'. This approach recognises that embodiment shapes a cultural mode of being and embodied preconceptions bring forth cultural intentionality which, in turn, frames embodied image schemas. The practical wisdom accompanying embodied capabilities of actors, frequently referred to as phonesis or embodied skill, 'pathic' competences and corporeal 'know-how' appear as the main target of interest here. For van Manen (2007: 20) embodiment facilitates a pathic and pragmatic 'grasp' of the world so that "the act of practice depends upon the sense and sensuality of the body, personal presence, relational perceptiveness, tact for knowing what to say and do in contingent situations, thoughtful routines and practices, and other aspects of knowledge that are in part pre-reflective, pre-theoretic, pre-linguistic". Such unconsciously embodied 'pathic' influences are too important to be regarded as simply a subcategory of communication because "our gestures, the way we smile, the tone of our voice, the tilt of our head, and the way we look the other in the eye are expressive of the way we know our world and comport ourselves" (van Manen, 2007: 22). Consequently, an unconscious embodied approach fully supports the proposition that communication is initially an unconscious embodied process (Ashcraft et al., 2009; Wright, 2017) as much as it is connected to reason and consciousness. Unconscious embodiment effects are more commonly explored through participant observation or projective techniques, which seek to surface an understanding or stimulate behaviours or expressions that can be attributed to unconscious embodied sources. Chia and Holt (2006), in pursuit of a 'practice turn' propose using participant observation of everyday 'sayings and doings' of practitioners in order to identify the embodied skills underpinning the practical logic or wisdom required to understand the 'autopoetic' practices of actors. A plethora of other similar approaches and techniques are available for the researcher interested in unconscious embodiment. These include but are not restricted to 'organizational aesthetics' (Strati, 2003), embodied narrative 
sensemaking (Cunliffe and Coupland, 2012; Cunha et al., 2015), embodied innovation (Sørensen, 2006), embodied teamwork (Hindmarsh and Pilnick, 2007), embodied ethics (Hancock, 2008), embodied identities (Kašperová and Kitching, 2014; Courpasson and Monties, 2017), and the use of film-elicitation techniques to explore embodied organizational practices (Skjaelaaen et al., 2018).

Within cultural research involving international management, Lowe et al. (2015) have studied a Chinese multinational subsidiary in Bangkok, Thailand to explore the connections between raw 'lived' embodied experience, language and cognition. They figuratively liken the relationship between body, language and thought to a cooking process and employ embodied realism (Lakoff and Johnson, 1999) to generate embodied models using LEGO. These are physical analogues that enabled narrative projections of latent, unconscious embodied sentiments about intercultural relations between Chinese managers and Thai employees. This form of embodied realism or embodied cognition appears more developed in business strategy research and consultancy. It is central to the work of Bürgi et al. (2005), who explain how strategy is crafted as an embodied practice of recursive enactment and in Jacobs and Heracleous (2006), who got interlocutors to build LEGO models as physical metaphors to project representations perceived strategic realities emanating from unconscious embodiment. The use of LEGO model analogues as a projective catalyst for unconscious images in analogically mediated inquiry (Barry, 1994) 'makes the invisible visible' by stimulating narratives about unconscious embodied motives and desires. In most cases, this abductive process provides catharsis, surfacing and sometimes resolution of latent, unspoken problems within business relationships caused by repressed, unconsciously embodied negative emotions.

\section{A QUEUE-GLOBE paradigm crossing approach}

Cultural subjectivities have largely been explored in international management research through a dualistic, objectivist prism (Sackmann and Phillips, 2004; Caprar et al., 2015; Patel, 2017; Romani et al., 2018). Deeper cultural subjectivities related to unconscious embodied forces have been almost entirely overlooked as a result. These deeper unconscious influences are not articulated, not consciously reasoned about, undisclosed and not directly measurable. Explorations of these unconscious embodied forces may not be explored optimally within an objectivist paradigm. This depth of subjectivity requires a complementary subjectivist approach borrowing from interpretivism, psychoanalytic theory, arts and humanities. 
In furtherance of this idea, mixed methods research has been described as a third research 'paradigm' to complement quantitative objectivism and qualitative subjectivism (Johnson et al., 2007; Creswell and Creswell, 2017). In 'pure' mixed methodology, equality is afforded to both objective and subjective criteria for research design, operation and analysis. It employs comprehensive 'triangulation' involving, where necessary, 'between-method' combinations of triangulation in data, investigators, theories and methods (Denzin, 1978). Mixed method approaches, generally emphasise that a main purpose is to account for living dynamics of phenomena and to take account of temporality. The common emphasis here is to understand complex living, evolving phenomena in motion rather than taking 'still' pictures of them.

As a first step, what follows is an outline of a 'sequential' paradigm crossing approach, which proposes that a QUEUE investigation of unconscious embodied cultural influences can be profitably used to identify whether participants in such an exercise subsequently respond differently to GLOBE questions relating to social values and practices than a control group of non-participants. The proposed research procedure involves splitting participants in two international locations of a multinational company into two groups, forming four groups in total. In each location one 'experimental group' is enrolled into an embodied realism exercise using LEGO to encourage participants to create physical analogues about their cross-cultural experiences, so stimulating their latent unconscious embodiment. The other 'control' group in each location is not enrolled in the LEGO model-building exercise. On completion of this first stage, all participants are asked to answer a questionnaire including GLOBE questions about social values and social practices. The results are then compared in order to determine if there are any significant differences between experimental and control groups, particularly in relation to correlations between social values and social practices. In this way, inferences can be made about cultures consequences of deep, unconscious embodiment in relation to conscious cultural values and practices.

The discussion so far has suggested that culture in international management can be productively explored as a paradox. Paradox has often been explained using the yin/yang symbol, which reflects dualities of both /and contradictions that are mutually constitutive. A consequence is that at the putative unconscious embodied level of culture, there are no variables at play because there are no stable or recognizable factors representing entitative phenomena. Paradoxically, therefore, cultures are phenomenological elements arising in consciousness and constituted by indeterminate and inchoate forces within an 'empty' unconscious. The enigma is how in such a duality, objects appear in consciousness out of apparently empty dualities of unconscious nothings or voids. 
The approach proposed here does not take up the solipsism implicit in the latter view and proposes a method where interactions between unconscious embodied and cognitively conscious cultural forces can be explored together. A sequential paradigm crossing approach is proposed, which suggests that a QUEUE investigation of unconscious embodied cultural influences can be usefully employed to identify whether 'experimental group' participants in such an exercise subsequently respond differently to GLOBE questions relating to social values and practices than a control group of non-participants.

\section{Stage 1: A QUEUE analysis using an embodied realism methodology}

Embodied realism (Lakoff and Johnson, 1999) is a QUEUE approach proposing that the mind is embodied, mostly unconscious, and embodied metaphors are the main vehicle for expressing abstract concepts. The implication is that "bodily experience both precedes and shapes conscious processes of thinking and interacting with the world" (Lowe et al., 2008: $50)$.

Through creation of physical analogues and a subsequent creative metaphor-elicitation process participants are able to gain indirect access to unconscious, embodied experiences (emotions, intuitions, perceptions and bodily sensations). The objects and models constructed by participants are 'embodied metaphors' which are "constructed through engagement of the body" (Heracleous and Jacobs, 2008: 53). Analogically-based methods link manual and cognitive activities providing participants an opportunity to 'think with their hands'. These and similar techniques have been used most successfully in corporate strategy consulting (Heracleous and Jacobs, 2008; Statler et al., 2008). In the context of culture, therefore, embodied realism would seek to get interactants from different cultural backgrounds to build analogues of their cultural relationships and experiences in order to allow them to begin to articulate feelings and intuitions about their unconscious embodied cultural experiences that are otherwise ineffable, intuitive and affective. This would be a vehicle for accessing their unconscious embodied 'sensing' of cultural exchanges through embodied metaphors that presage their more conscious sensemaking.

Initially, a cross-cultural approach using embodied realism requires equivalent samples from two international locations, which would ideally be from the same multinational company. Following the advice of Hofstede (1980, 2001), using samples from the same international company enhances the principal requirement in cross-cultural surveys for functional equivalence. He points out that the measures focus upon the differences between the samples rather than the absolute numbers. The implication is that the differences between 
narrow, functionally equivalent samples reflect differences between the populations they represent. Sample sizes do not, therefore need to be very large to satisfy the requirements of functional equivalence. It is therefore proposed that $\mathrm{N}$ of 50 in each international location is sufficient. These samples of 50 should be equally divided in both locations into a participant group (in the embodied realism exercise) and a control group that are not asked to participate. Participants should be sub-divided into working groups of five within groups in both locations.

In the embodied realism exercises, participants in both locations should be encouraged initially to individually use LEGO bricks to create their perceived images of their most memorable cross-cultural experiences. This initially stage, familiarisation with LEGO model building as physical analogues is the main purpose. Moderators might show photographs of models from previous exercises of this kind (Lowe et al., 2015; Kainzbauer and Lowe, 2018). At this point, it helps to let participants understand that it is not an accurate representation that is important, but rather their imaginative interpretation of the symbols involved. After building their LEGO models, participants should be asked to give a narrative interpretation of the physical metaphor they have built (each presents his/her own model to the other team members). In order to encourage further reflection, the moderator should ask a number of open questions about the physical metaphors developed by the participants. In order to ensure a smooth debriefing process, it is useful to have one moderator per group of five who stays with this team during the workshop.

During the next stage, participants should be encouraged to build another LEGO model of their individual view of a perceived cross-cultural problem within their work-life. Again, individuals need prompting to narrate their interpretations of their own model with colleagues (involving story-telling and reflective conversations) and answer questions related to the model. Group members should then be asked to combine individual models to form a combined, negotiated view of perceived cross-cultural issues and problems facing the company. At this point, the group spends some time building and discussing (framing) their consolidated understanding of the perceived issues. In the final stage, the group uses their consolidated understanding to build one final model representing their reflections of a collective view of cultural life. In the subsequent reflective conversations, group members should be asked to elaborate on how an 'ideal situation' could be achieved, thus developing input for possible solutions to any cross-cultural problems. The ideal solution should then be a referent for stimulation of comparison with both existing practices and narratives concerning how practices might change to accommodate an ideal situation. In debriefing, 
participants should be asked to reflect on their learning experiences and provide feedback on how they perceive the usefulness of the model-building of physical metaphors in terms of emergent feelings, concepts, terms and ideas in relation to intercultural interaction within their cross-cultural business relationships. For more details on how to use this embodied realism methodology see Lowe et al., 2015; Kainzbauer and Lowe, 2018.

\section{Stage 2: Administering a GLOBE questionnaire exploring social values and practices}

An unexpected outcome of the GLOBE (House et al., 2004) study was the counterintuitive finding significant negative correlations between social values and practices for most of the framework's cultural dimensions. In an examination of these issues, Taras et al. (2010) argue that the relationship between social values and practices is probably far more complex than previously assumed. They explore alternative explanations that incorporate cognitive dissonance, incomplete internalization of values into norms, sub-cultural heterogeneity, anchoring and priming in questions, level of analysis reference shift, and various issues of data analysis. Adding to the complexity, this paper proposes to add 'unconscious embodied' cultural influences to the mix, investigation of which would require adoption of methods outside of the prevailing positivism in studies of culture, management and organization.

Following the QUEUE exercise outlined above, it is suggested that a GLOBE questionnaire be distributed to the two experimental groups and the two control groups. Answers can then be analysed using the GLOBE approach to measure correlations between experience group participants and control group participants. Any unexplainable difference between these correlations and the original GLOBE correlations can then be attributed to the fact that the control group have had their unconscious embodied imagination stimulated by the QUEUE exercise and the control group have not. This is unlikely to explain how unconscious embodiment has an affect and only if there appears to be an effect. Any significant difference, however, would suggest that the entire programme of cross-cultural research in organizations needs to begin to take a step outside of its predominantly objectivist, positivist methodologies and engage with other paradigms and multi-methods more suited to exploring enigmatic and difficult to measure influences of the unconscious psyche. No significant differences between experimental and control groups would seem to indicate that unconscious embodied cultural influences are not a significant influence that we need to address and would justify a return to and the agenda of Taras et al. (2010) to explore empirically measurable 'factors' as a more suitable path to take. 


\section{Conclusions}

We have proposed that culture when understood as a paradox can be seen as constituted by contradictory yet mutually constituted opposite forces. The phenomenological aspects of culture which appear in consciousness offer direct and measurable empirical access and have been extensively examined through the 'national cultural model' over the last $40+$ years. However, the enigma of a negative correlation between social values and social practices in the GLOBE research stimulates the possibility of realising that there are cultural influences at play which are immeasurable but still require scrutiny. A more nebulous, pre-linguistic and embodied unconscious aspect of culture, it is suggested, has been largely overlooked, not least because it is not directly accessible through metrics. This undisclosed, noumenal aspect of the cultural paradox is not directly examinable and not suitable for positivist methodologies. A QUEUE methodology is proposed to determine whether the penumbra of embodied unconscious culture appears in GLOBE research. This aims to further explore possible reasons for the counter-intuitive negative correlations between social values and social practices found in the GLOBE data. The methodology proposes a means to judge whether GLOBE respondents respond differently to questions if they have been subject to a QUEUE exercise that stimulates their embodied unconscious imagination.

The main contribution of the paper rests in the suggestion that culture should be conceived as a duality between two contrasting yet co-determined spheres of conscious and unconscious aspects.

Traditionally, an over reliance on objectivism and a primary focus on measurable aspects of cultures have restricted or 'shackled' cultural explorations in international management. These 'shackles' (Lowe, 2002) of objectivist dualism are inclined to lead to an easy-tounderstand but, ultimately, simplistic appreciation of culture. They entail the "boxing of fluid phenomena into rigid pre-established categories" (Chia and Nayak, 2017: 130). They exclude the complexities and paradoxes of cultural context and tend to avoid the important esoteric understandings of indirect symbolic activities. In the terms used in this paper, they limit cultural investigations to 'half a story'. Our 'bi-focal' approach promises to unshackle cultural research and address cultural paradoxes on their own terms.

For Osland and Bird (2000), cultural paradoxes reveal the limits of simplistic characterizations of culture. "The limitations of sophisticated stereotyping become most evident when we confront cultural paradoxes. This is the moment we realize our understanding is incomplete, misleading, and potentially dangerous. Perhaps because cultural paradoxes reveal the limitations in our thinking, they are often left unmentioned, even though 
virtually anyone with experience in another culture can usually identify one or two after only a moment's reflection" (Osland and Bird, 2000: 67).

The paradox of culture creates many dilemmas. Culture paradoxically includes both things that are mostly tangible and processes that are mostly not. Jones (2013) suggests that culture involves both 'nouns' describing etic cultural structures and 'verbs' involving processes of emic cultural practices and activities. However, the tendency seems to have been to prefer nouns in describing 'culture', viewing it as a fixed product as opposed to a social process, which would more accurately be represented with verbs (Block, 2013). The alternative of prioritizing verbs, processes and practices carries a similar problem of tending to exclude nouns, structures and material conditions. It may be that a greater use of gerunds in cultural descriptions could be a way of overcoming this kind of cultural dualism, in which case 'culturing', valuing' and 'practicing' culture seem to be better terms to avoid binary dualism and provide vocabulary more accommodative of cultural duality.

Cultural paradoxes are a target of cross-cultural studies addressed by Li (2016) as well as Fang (2005-6; 2009). Fang (2005-6; 2009) explores some of the important implications of Eastern (Yin - Yang) dualities and calls for the application of indigenous Asian wisdom to advance management knowledge. In pursuit of a more 'emic-etic' approach to cultural understanding, Li (2016) proposes that Yin-Yang dualities are more consonant with paradox management than Western dualistic logic. From this perspective, paradox can be understood as a polarized mental condition that results from an inability to cognitively cope with complexity in terms of its inherent holistic, dynamic dualities and its emergent and 'becoming' character. Prevailing binary dualism within Western thought, which can be traced back to Aristotle, is regarded by Li (2016) as a symptom of this cognitive incapacity that limits understanding of complexity and paradox. By implication, accelerated adoption and incorporation of Eastern philosophies, which are more oriented towards complexity, paradox and ambiguity, is increasingly necessary as Western binary dualism increasingly flounders in global conditions of increasing complexity. The distinction between Eastern duality and Western paradox is subtle yet profound. The implication is that paradox is a cultural consequence of phlegmatic Western 'relativity avoidance' and persistent adherence or holding onto absolute distinctions. Eastern understanding of processes of emergence involves a permanently evolving 'becoming' as there is no absolute end-point where separation or unity become fixed, permanent or absolute. Eastern duality describes a perpetually relative evolving and revolving uncertainty and non-binary impermanence. Neither side of this impermanent, dynamic, relative duality can transform onto its opposite 
and both sides are permanently both partially complementary and conflicting, requiring perpetual re-balancing and re-adjustments at 'threshold' points between them. Li (ibid) asserts that Yin-Yang balancing can be practically applied to the most salient paradoxes of management including structure-agency and etic-emic dualities. In terms of cross-cultural management, a yin-yang balancing would support greater balance between etic universalism and emic particularization.

In order to explore culture as paradox, we propose unshackling cultural investigations by promoting the use of two halves of a story, including both cognitive and embodied cultural tales. A combination of objectivist/rationalist research methodologies used for exploring explicit aspects of culture, and a complementary qualitative analysis directed at more nebulous cultural phenomena may provide a more balanced analysis of culture as paradox. As such, the proposition is that this more complete narrative promises a more compelling cultural research saga which enlarges our conceptual understanding of cross-cultural issues through paradoxical reasoning (Gannon, 2008).

The novelty provided by our approach is in following Chia and Nayak's advice to take paradox "more lightly and playfully" (2017: 139) by adopting a duality instead of the prevailing dualisms embraced by most cultural research. Duality favours a 'both / and' approach rather than an 'either / or' reductionism. In particular, duality enables the paradoxes that Osland and Bird (2000) identify as ignored by dualistic approaches to become central features of cultural investigation. 


\section{References}

Arnaud, G. and Vanheule, S. (2013), "Lacanian psychoanalysis and management research: On the possibilities and limits of convergence", Management Decision, Vol. 51 No. 8, pp. 1664-1677.

Ashcraft, K., Kuhn, T. and Cooren, F. (2009), "Constitutional amendments: "Materializing" organizational communication”, Academy of Management Annals, Vol. 3, pp. 1-64.

Ashforth, B.E. and Reingen, P.H. (2014), "Functions of dysfunction: Managing the dynamics of an organizational duality in a natural food cooperative", Administrative Science Quarterly, Vol. 59 No. 3, pp. 474-516.

Barry, D. (1994), "Making the invisible visible: Using analogically-based methods to surface unconscious organizational processes", Organization Development Journal, Vol. 12 No. 4, pp. 37-47.

Beugelsdijk, S., Kostova, T. and Roth, K. (2017), "The impact of Kirkman, Lowe and Gibson's article on country level research in international business", Journal of International Business Studies, Vol. 48 No. 1, pp. 30-47.

Blackler, F. (1995), "Knowledge, knowledge work and organizations: An overview and interpretation", Organization Studies, Vol. 16 No. 6, pp. 1021-1046.

Block, D. (2013), "The structure and agency dilemma in identity and intercultural communication research", Language and Intercultural Communication, Vol. 13 No. 2, pp. 126-147.

Boyacigiller, N.A. and Adler. N.J. (1991), “The parochial dinosaur: Organizational science in a global context”, Academy of Management Review, Vol. 16 No. 2, pp. 262-290.

Brewer, P. and Venaik, S. (2010), "GLOBE practices and values: A case of diminishing marginal utility?”, Journal of International Business Studies, Vol. 41 No. 8, pp. 13161324.

Bürgi, P.T., Jacobs, C.D. and Roos, J. (2005), "From metaphor to practice: In the crafting of strategy", Journal of Management Inquiry, Vol. 14, pp. 78-94.

Burrell, G. and Morgan, G. (1979), Sociological Paradigms and Organisational Analysis, Heinemann, London.

Caprar, D.V., Devinney, T.M., Kirkman, B.L. and Caligiuri, P. (2015), “Conceptualizing and measuring culture in international business and management: From challenges to potential solutions", Journal of International Business Studies, Vol. 46, pp. 10111027.

Chen, C.C. (2018), "Yin-yang dialectics and communitarianism in cross-cultural management research", Cross Cultural \& Strategic Management, Vol. 25 No 3, pp. $492-500$. 
Chia, R. (2019), "Before and beyond paradigms in organization studies: Back to the "rough ground"”, Studi di Sociologica (Accepted for publication).

Chia, R. and Nayak, A. (2017), "Circumventing the logic and limits of representation: otherness in east-west approaches to paradox approaches", in Smith, W.K, Lewis, M.W, Jarzabkowski, P. and Langley, A. (Eds.), Handbook of Organizational Paradox, Oxford University Press, pp. 125-140.

Chia, R. and Holt, R. (2006), "Strategy as practical coping: A Heideggerian perspective", Organization Studies, Vol. 27 No. 5, pp. 635-655.

Courpasson, D. and Monties, V. (2017), ““'I am my body”. Physical selves of police officers in a changing institution", Journal of Management Studies, Vol. 54 No. 1, pp. 32-57.

Creswell, J.W. and Creswell, D. (2017), Research Design: Qualitative, Quantitative, and Mixed Methods Approaches, SAGE Publications, Los Angeles.

Csordas, T.J. (1993), "Somatic modes of attention", Cultural Anthropology, Vol. 8, pp. 135156.

Cunha, M.P., Clegg, S., Rena, A. and Gomes, J.F.S. (2015), "Embodying sensemaking: Learning from the extreme case of Vann Nath, prisoner at S-21", European Management Review, Vol. 12 No. 1, pp. 41-58.

Cunliffe, A. and Coupland, C. (2012), "From hero to villain to hero: Making experience sensible through embodied narrative sensemaking", Human Relations, Vol. 65 No. 1, pp. 63-88.

Damasio, A.R. (1996), "The somatic marker hypothesis and the possible functions of the prefrontal cortex", Philosophical transactions of the Royal Society of London, Series B, Biological Sciences, Vol. 351 No. 1346, pp. 1413-1420.

Denzin, N.K. (1978), The Research Act: A Theoretical Introduction to Sociological Method, Praeger, New York.

Devinney, T.M. and Hohberger, J. (2017), “The past is prologue: Moving on from culture's consequences", Journal of International Business Studies, Vol. 48 No. 1, pp. 48-62.

Fang, T. (2005-2006), "From “Onion" to "Ocean": Paradox and change in national cultures", International Studies of Management and Organizations, Vol. 35, pp. 71-90.

Fang, T. (2009), "Asian management research needs more self-confidence: Reflection on Hofstede (2007) and beyond", Asia Pacific Journal of Management, Vol. 27, pp. 155170.

Fotaki, M., Long, S. and Schwartz, H.S. (2012), "What can psychoanalysis offer organization studies today? Taking stock of current developments and thinking about future directions", Organization Studies, Vol. 33 No. 9, pp. 1105-1120. 
Gabriel, Y. (1995), "The unmanaged organization: Stories, fantasies and subjectivity", Organization Studies, Vol. 16 No. 3, pp. 477-501.

Gabriel, Y. and Carr, A. (2002), "Organizations, management and psychoanalysis: An overview”, Journal of Managerial Psychology, Vol. 17 No. 5, pp. 348-365.

Gannon, M. (2008), Paradoxes of Culture and Globalization, Sage, Los Angeles, CA.

Gibson, J.J. (1966), The Senses Considered as Perceptual Systems, Houghton Mifflin Co., Boston.

Hancock, P. (2008), "Embodied generosity and an ethics of organization", Organization Studies, Vol. 29 No. 10, pp. 1357-1373.

Henderson, J. (1990), Shadow and Self, Chiron Publications, Wilmette, IL.

Heracleous, L. and Jacobs, C.D. (2008), "Understanding organizations through embodied metaphors", Organization Studies, Vol. 29 No. 1, pp. 45-78.

Hindmarsh, J. and Pilnick, A. (2007), "Knowing bodies at work: Embodiment and ephemeral teamwork in anaesthesia", Organization Studies, Vol. 28, pp.1395-1416.

Hofstede, G. (1980), Culture's Consequences: International Differences in Work-Related Values, Sage Publications, Beverly Hills, CA.

Hofstede, G. (2001), Culture's Consequences: Comparing Values, Behaviors, Institutions, and Organizations across Nations, (2 ${ }^{\text {nd }}$ Ed.), Sage Publications, London.

House, R.J., Hanges, P.J., Javidan, M., Dorfman, P.W. and Gupta, V. (Eds.) (2004), Culture, Leadership, and Organizations: The GLOBE Study of 62 Societies, Sage Publications, Thousand Oaks, CA.

Jackson, W.A. (1999) "Dualism, duality and the complexity of economic institutions", International Journal of Social Economics, Vol. 26 No. 4, pp. 545-558.

Jacobs, C.D. and Heracleous, L. (2006), "Constructing shared understanding: The role of embodied metaphors in organizational development", Journal of Applied Behavioral Science, Vol. 42, pp. 207-226.

Johnson, R.B., Onwuegbuzie, A.J. and Turner, L.A. (2007), "Toward a definition of mixed methods research", Journal of Mixed Methods Research, Vol. 1 No. 2, pp. 112-133.

Jones, R. (2013), "The paradox of culture in a globalized world", Language and Intercultural Communication, Vol. 13 No. 2, pp. 237-244.

Kainzbauer, A. and Lowe, S. (2018), "Embodied realism by design in Thai management education", The International Journal of Management Education, Vol. 16, 281-291.

Kašperová, E. and Kitching, J. (2014), “Embodying entrepreneurial identity”, International Journal of Entrepreneurial Behavior and Research, Vol. 20 No. 5, pp. 438-452. 
Kastanakis, M. and Voyer, B.G. (2014), "The effect of culture on perception and cognition: A conceptual framework", Journal of Business Research, Vol. 67 No. 4, pp. 425-433.

Keller, J., Loewenstein, J. and Yan, J. (2017), "Culture, conditions and paradoxical frames", Organization Studies, Vol. 38 No. 3-4, pp. 539-560.

Kirkman, B.L., Lowe, K.B. and Gibson, C.B. (2006), “A quarter century of culture's consequences: A review of empirical research incorporating Hofstede's cultural values framework", Journal of International Business Studies, Vol. 37 No. 3, pp. 285-320.

Kluckhohn, F. and Strodtbeck, F.L. (1961), Variations in Value Orientations, Evanston, Peterson, IL.

Küpers, W.M. and Pauleen, D. (2015), "Learning wisdom: Embodied and artful approaches to management education”, Scandinavian Journal of Management, Vol. 31, pp. 493500 .

Lakoff, G. and Johnson, M. (1999), Philosophy in the Flesh: The Embodied Mind and its Challenge to Western Thought, Basic Books, New York.

Li, P.P. (2016), "Global implications of the indigenous epistemological system from the East: How to apply Ying-Yang balancing to paradox management", Cross Cultural \& Strategic Management, Vol. 23, No.1, pp. 42-77.

Lowe, S. (2002), "The cultural shadows of cross cultural research: Images of culture", Culture and Organization, Vol. 8 No. 1, pp. 21-34.

Lowe, S., Carr, A. and Moore, F. (2007), "Paradigmapping studies of culture and organization", International Journal of Cross Cultural Management, Vol. 7 No. 2, pp. $237-250$.

Lowe, S., Ellis, N. and Purchase, S. (2008), "Rethinking language in IMP research: Networking processes in other words, The Scandinavian Journal of Management, Vol. 24, pp. 296-307.

Lowe, S., Kainzbauer, A., Tapachai, N. and Hwang, K-S. (2014), "Ambicultural blending between Eastern and Western paradigms", Culture and Organization, Vol. 21 No. 4, pp. 1-17.

Lowe, S., Kainzbauer, A., Magala, S. and Daskalaki, M. (2015), "International business and the Balti of meaning: Food for thought", Journal of Organizational Change Management, Vol. 28 No. 2, pp. 177-193.

McSweeney, B. (2009), "Dynamic diversity: Variety and variation within countries", Organization Studies, Vol. 30 No. 9, pp. 933-957.

Merleau-Ponty, M. (1962), Phenomenology of Perception, Routledge, London. 
Michel, A. (2015), "Dualism at work: The social circulation of embodiment theories in use", Signs and Society, Vol. 3 No. S1, pp. S41-S69.

Osland, J.S. and Bird, A. (2000), "Beyond sophisticated stereotyping: Cultural sensemaking in context", Academy of Management Executive, Vol. 14 No. 1, pp. 65-79.

Patel, T. (2017), "Multiparadigmatic studies of culture: Needs, challenges, and recommendations for management scholars", European Management Review, Vol. 14, pp. 83-100.

Romani, L., Mahadevan, J. and Primecz, H. (2018), "Critical cross-cultural management: outline and emerging contributions", International Studies of Management \& Organization, Vol. 48 No. 4, pp. 403-418.

Sackmann, S.A. and Phillips, M.E. (2004), "Contextual influences on culture research: Shifting assumptions for new workplace realities”, International Journal of Cross Cultural Management, Vol. 4 No. 3, pp. 370-390.

Schultz, M. and Hatch, M-J. (1996), "Living with multiple paradigms: The case of paradigm interplay in organizational culture studies", Academy of Management Review, Vol. 21 No. 2, pp. 529-557.

Schwartz, S.H. (1992), "Universals in the content and structure of values: Theoretical advances and empirical texts in 20 countries", Advances in Experimental Social Psychology, Vol. 25, pp. 1-66.

Singer, T. and Kaplinsky, C. (2010), "Cultural complexes in analysis", in Stein, M. (Ed.), Jungian Psychoanalysis: Working in the Spirit of C.G. Jung, Open Court Publishing Company, Chicago: IL, pp. 22-37.

Skjaelaaen, G.R., Bygdås, A.L. and Hagen, A.L. (2018), "Visual inquiry: Exploring embodied organizational practices by collaborative film-elicitation", Journal of Management Inquiry, DOI: 10.1177/1056492618778138.

Smircich, L. (1983), "Concepts of culture and organizational analysis", Administrative Science Quarterly, Vol. 28, pp. 339-358.

Smith, W.K. and Lewis, M.W. (2011), "Toward a theory of paradox: A dynamic equilibrium model of organizing", Academy of Management Review, Vol. 36 No. 2, pp. 381-403.

Sørensen, B.M. (2006), "Identity sniping: Innovation, imagination and the body", Creativity and Innovation Management, Vol. 15 No. 2, pp. 135-142.

Statler, J., Jacobs, J. and Roos, J. (2008), "Performing strategy: Analogical reasoning as strategic practice”, Scandinavian Journal of Management, Vol. 24, pp. 133-144.

Strati, A. (2003), "Knowing in practice: Aesthetic understanding and tacit knowledge", in Nicolini, D., Gherardi, S. and Yanow, D. (Eds.), Knowing in Organizations: A Practice-based Approach, Sharpe, Armonck: ME, pp. 53-75. 
Taras, V., Steel, P. and Kirkman, B.L. (2010), "Negative practice-value correlations in the GLOBE data: Unexpected findings, questionnaire limitations and research directions", Journal of International Business Studies, Vol. 41 No. 8, pp. 1330-1338.

Trompenaars, F. (1988), Riding the Waves of Culture, The Economist Books, London.

van Manen, M. (2007), "Phenomenology of practice", Phenomenology and Practice, Vol. 1 No. 1, pp. 11-30.

Varela, F.J., Thompson, E. and Rosch, E. (1991), The Embodied Mind: Cognitive Science and Human Experience, MIT Press, Cambridge: Mass.

Williams, A.M. (2007), "Listen to me, learn with me: International migration and knowledge transfer”, British Journal of Industrial Relations, Vol. 45 No. 2, pp. 361-382.

Wright, A. (2017), "Embodied organizational routines: Explicating a practice understanding", Journal of Management Inquiry, DOI: 10.1177/1056492617713717.

Yakushko, O., Miles, P., Rajan, I., Bujko, B. and Thomas, D. (2016), Cultural unconscious in research: Integrating multicultural and depth paradigms in qualitative research, Journal of Analytical Psychology, Vol. 61 No. 5, pp. 656-675. 